on the maximum points described by Dr. Henry Head. ${ }^{1}$ The maximum points on which the incidences of this form of greyness are most common are the upper mid-orbital and the occipital (Nos. I and 9 respectively in Fig. 1 ; compare Fig. 2). In this form of greyness there are other points of incidence whirh do nnt correspond to the maximum points described hy Dr. Head, but the sites of their occurrences are constant. One of these conatant points is $I_{2}^{1}$ in. above the pinns of the ear (see No. 4 in Fig. I). This constant point of incidence is

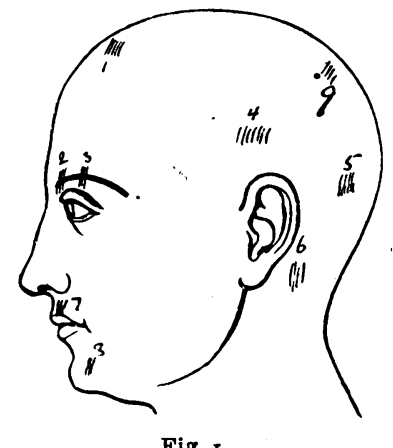

Fig. x.

too low for vertical or parietal maximum points : Captain Pinch, I.M.S., has seen a family in which the father and four sons had each a grey patch on this point. Another constant point is seen in No. 7 in Fig. 1 , situated in the moustache at a point which corresponds to the position of the lateral jncisor and canine teeth. It will be seen that the point is too internal for Dr. Head's maximum point for the naso-labial region (see Fig. 2).

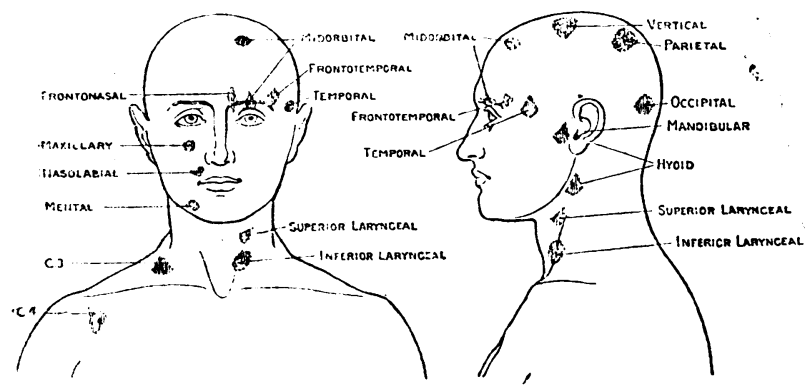

Fig. 2.

In this class I have seen in a boy a grey patch in the lower mid-orbital maximum point, and not the upper (see No. 3 in Fig. 1 ; compare with Fig. 2), and a grey patch in a man on the fronto-nasul point (see No. 2, Fig. I, and compare Fig. 2). I may mention under this class of case that I have seen bald patches on one side of the face which existed as far back as the man could remember; the sites of baldness were on Nos. 1 and 3 in Fig. I, and the naso-labial maximum point (compare with Fig. 2).

Greyness of Age.

$B$ and $C$. These types I classify together because they are popularly recognized as a natural consequence of age. I will describe the rarer condition (B) first. Here the incidence of gregness occurs in patches which are preliminary to a state of general diffuse and finally complete greyness. These precedent patches of greyness are also common on the maximum points described by Dr. Head, and the commonest points on which they are seen are the occipital and mental, and are often symmetrical. The most marked case I have seen, and which first called my attention to the matter, was pointed out to me in December, 1903, by Sir Victor Horsley. In this case the occipital and mental maximum points on each side were practically the only grey hairs visible, but now the greyness has become more general (see Nos. 5 and 8 in Fig. I ; compare with Fig. 2). I have seen cases begin to "go grey" on the point which is constantly appearing grey in Class $A$, namely, No. 4 in Fig. 1 , which I have indicated does not coincide with any of Dr. Head's maximum points. $C$, the aecond of the two forms of greyness acquired as a consequence of age, is by far the most common of any type I can describe. $\boldsymbol{L}$ ts incidence is characterized by scattered grey hairs usually in the region of the temples, the greyness then gradually becomes diffused and ends in total greyness.

Curiously enough, I have seen a woman whose hair became very grey during middle age, except on the right upper midorbital maximum point, on which the hair remained the same brown colour of girlhood and early womanhood (see No. I in Fig. I; compare with Fig. 2). I have not observed a case in which emotion or shock suddenly induced greyness, although the existence of such cases is recognized.

Finally, I have seen two cases in which the beard was grey in the area of distribution of the mental nerves of the two-tifths and so sharply limited to those areas that it is difficult to explain it by saying it was mere coincidence.

The points of incidence in certain forms of greyness may not be of intrinsic importance, but the facts form links in the chain of evidence connected with the obscure processes which are united under the vague term of "trophic disturbances."

Whether the neurotrophic influence, which seems to me to be inducing the hair's greyness, be due to central influences direct, or a peripheral modification of those central influences, as appears to me to be concerned in the etiology of cancer, I cannot accurately determine, for two reasons: First, according to Dr. Head, the commonly-described nerve areas of the head must be regarded as peripheral ; and, secondly, observations upon the incidence of the hair's greyness on the body are extremely difficult; and, according to $\mathrm{Dr}$. Head, it is the evidence shown by trunk-nerve areas upon which trust can be placed in estimating whether or no the nerve inflaence be central or peripheral in origin.

The difficulties of my position are obvious when I state that I have not seen any instance of hair on the body in which the hair covered three or even two maximum points of the same central or segmental nerve distribution. I can only say that I have seen men of middle age whose chests were covered with hair in which patches of greyness appeared on one or two points, but of different nerve areas. REFERENCE.

1 On the disturbances of sensation, with special reference to the pain of visceral disease. See Brain, vol. xvii.

\section{THE PERCEPTION OF LIGHT AND COLOUR.} By F. W. EDRIDGE-GREEN, M.D., F.R.C.S.

A THEORY to be of any use as a working bypothesis must be able to explain the main facts of the subject, and in addition there must be no definite fact which is totally at variance with it. I propose in this paper to show how the theory which I have promulgated will explain the known facts of light and colour vision, and how impossible it is to adopt any form of elemental hypothesis.

I assumed that light falling upon the ese liberates the visual purple from the rods (just as heat would melt an oint. ment) and a photograph is formed. The decomposition of the visual purple by light chemically stimulates the ends of the cones, and a visual impulse is set up which is conveyed through the optic nerve fibres to the brain. I assume that the visual impulses differ in character according to the wavelength of the light causing them; that is to say, a very similar condition exists in the impulses which are transmitted along the optic nerve to that which is accepted for waves of light previous to their entering the eye. The fibres of the optic nerve pass to the visual centre. I have assumed that the visual centre transmits to the mind impressions of white light, and that by it objects are seen monochromatically, as in a photograph. The visual centre is, therefore, acted upon by impulses caused by all rays of light, the colourperceiving centre being concerned with the quality of the impulse within the power of perceiving differences possessed by that centre or portions of that centre. It will be noticed that this theory consists of two distinct hypotheses-one retinal and the other cerebral. Each is supported by a separate series of facts. Each of these theories has enabled me to predict and subsequently ascertain the existence of a large number of new facts, most of which are quite inconsistent with any elemental hypothesis. In fact, the reader who is acquainted with the recent literature of this subject will see that other writers have, in addition to rediscovering many of my facts, arrived at a similar conclusion concerning them.

I will now review a certain number of facts of light and 
colour vision, and it will be seen that not only does the above theory give an explanation of them, but that they are a necessary consequence of it.

\section{I. - The Evolution of the Colour Sense.}

All the facts which can be obtained from the examination of museums or literature point to the view that the sense of light was drveloped first and then the sense of colour, those rays which differ most physically being the first to be differentiated. In the course of evolution all the varieties of psychophysieal colour blindness have been passed through. According to the theory I have given, we must suppose that the visual centre was first dev-loped, and subsequently a colourperceiving centre. When there were few cells in that centre it would only be able to differentiate between the largest and the smallest wave lengths, the red and the violet; that is, the opectrum appeared nearly all grey, but with a tinge of red at one end and a tinge of violet at the other. As the colour sense developed, and more and more cells were added to the colour-perceiving centre, it was not necessary that the rays of light should be so far apart before a difference was seen. and 80 the neutral band gradually diminished in size until the two colours met in the centre of the spectrum. Then a third colour, green, was developed, there being three points of difference seen, instead of two. Then a fourth colour, yellow, was developed, its position appearing at the n+xt point of difference-that is, midway between the red and the green. The next colour to be developed was blue, and then orange. In some individuals evolution has proceeded further, and $a$ seventh colour is seen in the spectrum.

\section{II.-Colour Blindness.}

Cases of colour blindness may be divided into two classes, which are quite separate and distinct from each other, though both may be present in the same person. In the first class there is light as well as colour loss. In the second class the perception of light is the same as in the normal sighted, but there is a defect in the perception of colour. In the first class certain rays are either not perceived at all, or very imperfectly. Both these classes are represented by analogous conditions in the perception of sounds. The first class of the colour blind are represented by those who are unable to hear very high or very low notes; the second class by those who possess what is commonly called a defective musical ear.

Clour-blind individuals belonging to this class can be arranged in a series. At one end of this series are the normal sighted, and at the other the totally colour blind. The colours appear at the points of greatest difference, and I have clasaified the colour blind in accordance with the number of colours which they see in the spectrum. If the normal sighted be designated hexachromic, those who see five colours may be called pentachromic ; those who see four, tetrachromic; those who see three, trichromic ; those who see two, dichromic; and the totally colour blind, monochromic. There are many degrees included in the dichromic class. There may or may not be a neutral band, and this is widest in those cases approaching most nearly to total colour blindness. I have recorded a case of a patient who was colour blind with one eje. It is an interesting fact that for form vision the colourblind eye was much the better of the two, and he could recog. nize fine lines in the spectrum with this eye which were not visible to the other. He saw the two ends of the spectrum tinged with colour and the remainder grey. It will be noticed that his colour sensations were limited to the extreme red and the extreme violet, namely, those colours which present the greatest physical contrast to each other. Neither the red nor the violet appeared of the nature of a primary colour, but gave the impression that they were largely diluted with grey.

No part of my work on colour vision has been less understood than that relating to the number of colours seen by different persons in the spectrum. When $I$ say that the normal sighted see six definite colours, I do not mean that they cannot see more than six differences of hue in the spectrum, but that they see six colours which appear to be primary. Yellow-green, for instance, is obviously not a primary colour, as we can recognize in it a yellow and a green element. If we examine the spectrum so that only a small portion is sf en at one time, either using a spectrosc spe with shutters to the eyepiece, or letting the spectrum pass through a slit which only allows a small portion to pass, we shall see that it apprars to be made up of a series of monochromatic bands. These bands differ in size with different persons according to their colour perception. A person with good colour perception can see about eighteen consecutive mono. chromatic patches in the spectrum. Those who possess a very good colour perception can see a few more, those with defective colour vision see a less number in proportion to the defect. The fact that a large portion of the spectrum appears monochromatic when isolated requires fxplanation on any colour theory; but the fact iteelf accounts for many of the mistakes of the colour blind. For instance, when we find that a man includes a large portion of the orange with the red, we are not surprised when he tells us that he cannot tell the calcium flame from the strontium. Defects of colour perception, where there is light as well as colour loes, may be due to one or more causes, all of which are probably peripheral. such as absorption by the media of the eye, or defect in the visual substauce. In the eecond class the colour blindness is due to a defective development of the colour-perceiving centre in the brain, the imperfect development preventing the act of perception from being perfect'y performed, and therefore similar impulses are regarded as the same. Colour blindness is therefore only a representative of an earlier state in the development of the colour-perceiving centre.

\section{III.-Colour Mixing.}

The facts of colour mixing are consistent with the above theory. If we regard the impulses caused by the decomposition of the visual purple by red and violet respectively to be the most unlike, then these impulses and the central one of those lying between them, namely, green, will form a natural trichromatic system. The explanation of the fact that red and green make yellow, and green and violet blue, is consistent with the evolutionary theory. In past ages all, as the trichromic do now, gaw the rainbow made of three coloursred, green, and violet. When a new colour (yellow) appeared between the red and green it was obviong that a mixture of red and green would give rise, not to red-green, bat to the colour which had replaced it, namely, yellow. I find that the proportions of red and green required to match a yellow depend largely upon the luminosity of the colourd. I find that I require nearly two and a half times as much green when the colours are bright as when they are of feeble luminosity. If the compound yellow and the simple yellow were phrsiologically the same, how can we account for this fact? If we suppose that the visual purple acts like other photo-chemical substances, and is differently acted upon according to the intensity of the light, we have a simple explanation of the fact.

Compound colours, when again mixed, do not give the same result as the simple colour with which they were first matched. If an elemental hypothesis were true, then a small addition of one colour to another should change the hue of the latter, but a considerable quantity of one colour may be added to another without producing any apparent change.

The fact that two colours when mixed will make white is a necessary consequence of the theory I have given, provided that these two colours represent, either dirently or indirect]y, all the colour seneations of the observer. When two complementary colours are mixed, the colour-perceiving centre is placed in a position in which it is not able to perceive ang colour, the colours neutralizing each other.

IV. - The Colour Vision of the Periphery of the Retina.

As an object is moved further from the centre of the field of vision we become more and more colour blind. 'This is consistent with the view that the macula, being more fully represented in the cortex, is in a higher state of development.

\section{V.-Contrast.}

A careful consideration of the facts will show that they may be classified under two heads:

I. Those due to the colour-perceiving centre in the brain.

2. Those due to colour fatigue of the retina and brain.

The first class includes all those changes in which a colour appears to be shifted to a higher or lower point in the colour scale. This is easily explained on the view that colour being a point of difference, this becomes more marked on comparison, the perceptive centre being in the most favourable position for the detection of any difference. As the facts are given differently in most books, i will give a quotation from Abney :1 "Except for the red and the violet. there is a tendency for the two colours to become more widely separated in the spectrum. Thus with red and yellow the red remains of the same hue, but appears slightly more saturated, whilst the vellow appears greener."

1 On the Measurement of colour Produced by Simulsaneous Contrast. Proc. Roy. Soc., 1894, p. 221. 
Successive contrast is explained by assuming that when the colour-perceiving centre in the brain has just been perceiving rays of a certain kind, it and the retina are directly afterwards less responsive to those rays than to rays of a different degree of refrangibility, and so surrounding objects will appear to be deficient in that colour.

VI.-Adaptation Corresponds to an Accumulation of Visual Purple in the Retina, thereby making it More Sensitive to Feeble Impressions of Light.

It is obvious that all the facts which have been brought forward in evidence of their being a visual substance are in favour of the theory I have given. I have examined the retinas of several monkeys after they had been kept in a dark room, and found that the visual purple was to be found in the yellow spot, but situated between, and not in the cones. A bright light may fall upon the fovea without producing any sensation, and a perceptible interval elapses before we are able to see with the yellow spot, after the remainder of the retina the fovea being the last point to convey a sensation of light. The first fact we should expect, the cones not being directly sensitive to light; the second corresponds to the diffusion into the yellow spot of the visual purple.

\section{THE ROYAL COLLEGE OF SURGEONS OF EDINBURGH ;}

ITS EARLY CONNEXION WITH MEDICAL TEACHING.

Bx R. McKENZIE JOHNSTON, M.D., F.R.C.S.EDin.,

Surgeon in Charge of the Ear and Throat Department, Royal Infirmary Lecturer to the University of Ediuburgh ; Examiner Royal College of Surgeons, Edinburgh.

IT is singularly difficult, during a brief sojourn on the banks of the Nile, to settle down to fulfil a promise to contribute a few lines to the JUURNAL on the occasion of the great centenary of the Royal College of Edinburgh. The corn and oil we read about is not much in evidence now, while the wine of old seems largely to have given place to a liquid originating in Scotland. Ink dries quickly, with the temperature ranging about $100^{\circ}$, but one's ideas seem to dry up even more rapidly. It is, however, easy to comprehend why Rzmeses and those who have followed after him found it convenient to adopt the night shirt as a suitable dress for the day time, and it is even ppssible to envy them their costume.

Sitting in theneighbournood of the tombs of the Pharaohs, in a land where everything is ancient, and among a people whose dress, "whose habits, whose customs, and mode of life show but little change in a thousand years, in spite of the many innovations introduced by the foreigner, a period of 400 years appears a comparatively short span of time. On the other hand, in our more northern land, it is difficult, almost impossible, to realize the extraordinary changes that have taken place in the social, political, religious and scientific life of our country during the period that has elapsed since 1505 .

An interesting account of the various charters granted to the College appeared in the Journal of March inth, from the pen of Dr. J. Smith, from which it appears that the College was founded in the reign of James IV, Henry VII being at the time King of England. Shortly afterwards an event of the first importance took place in the marriage of Margaret Tudor, sister of Henry VIII, to James of Scotland. The history of the times shows that Scotland was backward, was poor, was in constant trouble with its nobles, with the Highlanders, and with the sister country, and that frequent wars or rebellions interfered with the advancement of the country. James with all his faults did much to improve matters and to encourage literature and science.

Johin Knox, a name familiar in the religious history of Scotland, was probably born in 1505, the year the College was founded, although a recent controversy in which Andrew Lang took part, has tried to fix the correct date of his birth at 1513 . It may help us to realize what life must have been with us 400 years ago, if we recall the fact that printing was first introduced into Scotland only in the year 1508 , or three years after the foundation of the College, or again, that the Gunpowder Plot was discovered exactly ico years later, when Guy Fawkes was put to the torture in London in order to make him confess the plot. Numerous other historical events will no doubt occur to our readers, calculated to assist them in realizing the vast difference between the times then and now.
In 1505; medical teaching was not even in its infancy and the great medical faculty of the University, which we may justly claim to be the offspring of our College, was not founded till 1728. It was the recognition of the necessity for some form of medical education which czused our enlightened forefathers to apply for a charter, and thus came to be formed the "crait" or "incorporation of surgeon-barbers." Much wisdom by the founders is shown by the founders in the objects kept prominently in view, as the following extract will show.

". . . Item that no maner of persoun occupie nor use any poyntis of oure saidis craftis of Surregerie or barbour craft within this kurgh bott give be first frieman and burges of the samyn and that he be worthy and expert in all the poyntis belang and the saidis craftis deligentlie and avysitlie examinit and admittit be the maisteris of the said craft for the honorabill seruyng of oure Soveraine Lord his liegis and nychtbouris of this burgh. And als that everie man that is to be maid frieman and maister amagis was be examit and previt in their poyntis following. Thatt is to say that he knaw anotomea nature and complexioun of every member in manis bodie. And in lpkeways he knau all the vaynis of the samyn thatt he may mak flewbothomea in dew tyme. And als that he knau in quhilk member the signe hes domination for the tyme for every man aught to knaw the nature and substance of every thing that he wirkis or ellis he is negligent."

It is further evident that they $r \in$ cognized how, for the proper study of anatomy and surgery, practical opportunities were required. This explains the following request :

". . And that we may have anis in the yeir ane condamnit man efter he be deid to mak antomea of quhairthrou we may haif experience. Ilk ane to instruct utheris ..."

Nor was the necessity for preliminary education overlooked for the same deed contains probably the earliest reference to it. Fven though it may hardly come up to the present-day requirements of the Gentral Medical Council, it was a commencement:

". . . Item that na maisteris of the said craft sall tak ane prenteis or feit man in tyme cuming to use the surregeane craft without he can baith wryte and reid."

For the protection of the general public against quacks and unqualifed practitioners definite powers were granted, and if these powers have now expired, we could wish them reinstituted in the present day. Quoting from the eame deed we find it was:

"... Ordained for the good of the lieges that in the mater belonging to the arte of chirurgerie they be provydit witte skillfull and honest men and not left to the arbitrament and impnstour of woman and ignoranttis. . . Thairfore $\mathrm{His} M+$ jestie with advyse foresaid discharges all and quhatsumevir persones (except they be friemen of the said craft in Edinburgh) to use and exerce any point of the arte of chyrurgerie within the said burgh of Edinburgh or any subsurbis about the samene or belonging thalrto and jurisdictione thairof. With power to the Deacone and Masteris of the said arte present and to cum at all tymes convenient to pas search seik tak and apprehend all sich (such) persones exercing the said arte within the said burgh subsurbis and jurisdictione thairof foirsaid not being friemen of the said arte within the said burgh and to caus thame set cautioun to desist in tym cumming and gif they failyie to unlaw thame in the sowme of twentie poundis money toties quoties. ..."

One half of the fine went to the coffers of the College. It would appear that the benefits derived from these powers were such that William and Mary granted a fresh patent confirming the rights of the College, and extending the area of control, which patent was ratified by Parliament in 1695 .

Up to this time almost the only means of entering the profession or of medical education was through apprenticeship to one of the Fellows of the College. In 1694, however, Monteith, one of the members of the College, applied for some unclaimed bodies to enable him to give anatomical demonstrations, while a week later the College itself made a similar request to the Town Council. The lat ter was granted on the condition that the College should build a theatre within three years. This was completed in 1697 and for several years various Fellows gave demonstrations in it, until in 1705 it was decided to appoint Robert Ellint "our professor of anatomy." In the same year he applied to the town for encouragement, and was in consequence appointed Professor of Anatomy at an annual salary of $f_{0} 15$ ln 1720 this chair became vacant, and the College rfcords bear that "the hail calling being persuaded of the sufficiency of Alex Monro, one of their number, did unanimously recommend him . . . 